\title{
A DEVELOPMENT OF INTERACTIVE TASK GENERATOR BASED ON TASK LOCATION INFORMATION ANALYSIS
}

\author{
Sangyoon Chin ${ }^{1}$, Woo-Young Kang ${ }^{1}$, Yea-Sang Kim ${ }^{1}$, Kyungrai Kim ${ }^{2}$, Jai-Do Shin ${ }^{3}$ \\ ${ }^{1}$ Division of Architecture, Landscape Architecture \& Civil Engineering, SungKyunKwan University \\ schin@skku.ac.kr,nikki1@empal.com,yskim2@skku.ac.kr \\ ${ }^{2}$ Division of Architectural Engineering, Ajou University \\ kyungrai@ajou.ac.kr \\ ${ }^{3}$ Research Institute of Technology, Woonam Construction Corporation \\ doshin3@woonam.co.kr
}

\begin{abstract}
A daily report is one of the critical documents in construction projects, since it helps them keep track of various as-built information such as task performed, manpower, equipment, and material used on a daily basis. Despite the important role in progress management, the daily reporting process is time-consuming, and the representation of task information on daily reports are not effective enough to accumulate daily as-built information for further use in project management. Task information is composed of a specific work type and a location where the task is performed, which means that the same type of work is repeated over the locations. However, in many cases the task locations are described inconsistently depending on a reporter's preference or experience. Without representing task location information in a consistent and accurate manner, it is difficult to accumulate and to reuse as-built information. The objective of this research is to build a framework for generating task information which can be efficiently accumulated and reused for progress management. To do so, this research built a task information model with a focus on the representation of task location associated with a work type, based on the combination of location facets, such as site, building, floor, space, and element. Finally an information system was developed to support automated and interactive generation of task information.
\end{abstract}

Keywords: Daily Reports, Task, Location, Space, Information Model, Information System, Database

\section{INTRODUCTION}

A daily report is one of the critical documents in construction projects, since it helps them keep track of various as-built information such as tasks performed, manpower, equipment, and material used on a daily basis. Despite the important role in progress management, the daily reporting process is time-consuming, and the representation of task information on daily reports are not effective enough to accumulate daily as-built information for further use in project management.

Task information is composed of a specific work type and a location where the task is performed, which means that the same type of work is repeated over the locations. However, in many cases the task locations are described differently depending on a reporter's preference or experience. Without representing task location information effectively, it is difficult to accumulate and reuse as-built information. This problem can get even worse in an apartment housing project that has about 10 high-rise buildings of 20 to 25 stories with over 1,000 residential units.
The objective of this research is to build a framework for generating task information which can be efficiently accumulated and reused for progress management in an apartment housing construction project. To do so, this research built a task information model with a focus on the representation of task location associated with a work type, and developed an information system that supports automated and interactive generation of task information.

\section{TASKS AND DAILY REPORTS}

\subsection{Definition of a task}

Popescu [1] defined a task and an activity as follows: "A task is a constituent of an activity - a portion of an activity that has duration of less than the total duration of the activity, while an activity is the fundamental unit of work in a project plan and schedule. Each work activity has a defined geographical boundary, a concise description of the work to be performed, and an estimated duration during which the work can be performed. Activities can also have detailed resource and cost estimates." 
Based on the definition, a task in this research means that it is a unit for the daily progress management by each contract; it is performed by a single crew at a specific work location; and it is charged with by a specific contractor. In addition, in a sense that tasks represent more detailed unit than activities that are usually managed on a weekly or monthly basis, tasks are sub-activities of an activity.

\subsection{Tasks in daily reporting system}

Research needs on structuring the task information to resolve the cumbersome and error-prone process of daily reporting, and difficulties in accumulation of as-built information have been raised by a lot of researchers [2, 3, 4]. And others [5, 6] emphasized the importance of management at the task level, which is more detailed than at the activity level, for more accurate information management.

However, it seems that the problems are not quite resolved effectively at this point. Through site visit, exhibitions, and interviews with practitioners and system developers, existing daily reporting systems were surveyed and analyzed. The results show two patterns. First, there is lack of consideration for an information structure to present tasks in a consistent way. In this case, users input tasks performed on that day manually so that even the same type of tasks are presented differently due to an individual's preference for terminology or experience. In particular, work locations are inconsistently presented in the daily reports even by the same person. Secondly, although some systems have an information structure to present work locations, the structure has too little flexibility to present varied work locations. In this reason, locations are not presented effectively particularly for such tasks as finish work, interior work, etc.

\section{TASK INFORMATION MODEL}

\subsection{Analysis of task information on daily reports}

The analysis of daily reports used by general contractors in apartment housing projects shows that task information is collected on a daily basis, and is presented in the combination of a work type for the task and a work location where the task occurs. Work types are usually standardized at the company level, but locations are neither standardized nor consistent although they implicitly represent combination of building, floor, space, and element types of information. Table 1 shows how work types can be combined by buildings, spaces, and elements to make up task information in an apartment housing project. It is found that tasks of the majority of work types can be clearly presented by combination of building and floor information only. However, in several work types, such as finish works and interior works, information on various types of rooms, spaces, and elements often needs to be combined with variety in addition to information on buildings and floors to present tasks as shown in Table 1.

Examples on the combination patterns for tasks in Table 1 can also be varied depending on the characteristics of a project. For example, if the cost of a certain work type takes only a small portion in the total cost, only a few tasks for the work type might be necessary for progress management, and only one or two location items would be combined with the work type to present the tasks. However, in the opposite case, a lot of tasks at more detailed level might have to be made by combining as many location items as possible with the work type. Therefore the information structure for tasks should be flexible enough to present tasks with variety depending on work types and characteristics of a project while keeping consistent and standardized terms of work types, buildings, floors, spaces, elements, etc.

Table 1. Combination of work types and location facets

\begin{tabular}{|c|c|c|c|c|c|c|}
\hline \multicolumn{3}{|c|}{ Work types } & \multicolumn{4}{|c|}{ Location facets } \\
\hline \multirow{2}{*}{$\begin{array}{l}\text { High } \\
\text { level }\end{array}$} & \multirow{2}{*}{$\begin{array}{c}\text { Medium } \\
\text { level }\end{array}$} & \multirow[b]{2}{*}{ Low level } & \multirow[b]{2}{*}{ Bldg } & \multicolumn{2}{|c|}{ Spaces } & \multirow[b]{2}{*}{ Elements } \\
\hline & & & & Floor & $\begin{array}{l}\text { Room } \\
\text { or other } \\
\text { types }\end{array}$ & \\
\hline \multirow{6}{*}{ 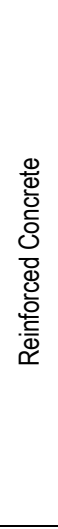 } & \multirow{3}{*}{$\begin{array}{l}\text { Form } \\
\text { work }\end{array}$} & $\begin{array}{l}\text { Lift gang } \\
\text { forms }\end{array}$ & $\bullet$ & $\bullet$ & & \\
\hline & & Erect forms & $\bullet$ & $\bullet$ & & $\begin{array}{l}\text { Column } \\
\text { Beam } \\
\text { Wall, } \\
\text { Slab } \\
\end{array}$ \\
\hline & & Strip forms & $\bullet$ & $\bullet$ & & $\begin{array}{l}\text { Wall, } \\
\text { Slab }\end{array}$ \\
\hline & \multirow[b]{2}{*}{ Rebar } & $\begin{array}{c}\text { Prepare } \\
\text { rebars }\end{array}$ & $x$ & $x$ & & \\
\hline & & Erect rebar & $\bullet$ & $\bullet$ & & $\begin{array}{l}\text { Column } \\
\text { Beam } \\
\text { Wall, } \\
\text { Slab }\end{array}$ \\
\hline & casting & $\begin{array}{l}\text { Placing } \\
\text { conc. }\end{array}$ & $\bullet$ & $\bullet$ & & \\
\hline \multirow{5}{*}{ 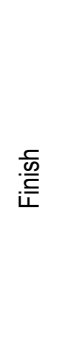 } & \multirow{2}{*}{$\begin{array}{c}\text { Interior } \\
\text { finish }\end{array}$} & $\begin{array}{l}\text { Plaster } \\
\text { Coat } 1\end{array}$ & - & $\bullet$ & $\begin{array}{l}\text { Bedroom, } \\
\text { Bathroom } \\
\text {, Kitchen, } \\
\text { Staircase }\end{array}$ & $\begin{array}{l}\text { Wall } \\
\text { Ceiling }\end{array}$ \\
\hline & & $\begin{array}{l}\text { Plaster } \\
\text { Cost } 2\end{array}$ & - & $\bullet$ & $\begin{array}{l}\text { Bedroom, } \\
\text { Bathroom } \\
\text {, Kitchen, } \\
\text { Staircase }\end{array}$ & $\begin{array}{l}\text { Wall } \\
\text { Ceiling }\end{array}$ \\
\hline & \multirow{3}{*}{$\begin{array}{c}\text { Exterior } \\
\text { finish }\end{array}$} & Finish Coat 1 & $\bullet$ & & & \\
\hline & & \begin{tabular}{|l|} 
Finish Coat 2 \\
\end{tabular} & $\bullet$ & & & \\
\hline & & Grinding & $\bullet$ & - & & \\
\hline
\end{tabular}

\subsection{Task information model}

Based on the analysis on task information mentioned above, information types and their relationships were identified with a focus on components of task 
information that are work types, buildings, spaces, and elements. An information model was developed to assign the combination of location-related facets into work types at the standard level, and it enables to modify the combination of locations so that tasks can be generated depending the characteristics of a given project.

To develop a task information model, the concepts from Uniclass [7] and Industry Foundation Classes (IFC) [8] were adapted. Kang and Paulson [9] insisted that existing classification systems are neither decomposed enough at more detailed level nor inclusive enough to support the presentation of construction projects at more detail level. Furthermore their successive research [10] recommended the utilization of faceted classification system like Uniclass rather than fixed hierarchical systems. Meanwhile, the primary IFC element hierarchy is based on that a project is a top-level container that has one or more sites; a site has one or more buildings; a building has one or more stories (floors); each story has spaces; and spaces are made up of one or more elements [11]. Therefore, this research utilized the facet concept from Uniclass for flexible combination, and the facets were derived from the element hierarchy concept from IFC. That is, project, site, building, floor, space, and element are combined with flexibility based on the characteristics of a work section and a project. As a result, the task information model is proposed as shown in Figure 1.

The task information model was developed by using the class diagram of Unified Modeling Language (UML) [12]. Each box represents a class and a line represents a relationship between two classes. In this model, Tasks has relationships with all other classes since instances for the Task classes are generated with combining a Work Item instance with instances of Sites, Buildings, Spaces, and Elements classes, where Spaces, in turn, has 4 subclasses. Floor information is not represented in a separate class in this model, since it is embedded as attributes in the Buildings class.

The Spaces class is specialized into various subclasses as shown in Figure 1, and they are referred to the space facet of Uniclass [7]. Table 2 shows some of instances for the subclasses. Since the subclasses are minimal to verify the concept of the task information model, additional classes as well as instances can be included as necessary.

Table 2 Instances in Spaces and Elements

\begin{tabular}{|c|c|c|c|c|}
\hline \multicolumn{4}{|c|}{ Subclasses of Spaces } & \multirow[b]{2}{*}{ Elements } \\
\hline $\begin{array}{c}\text { Vertically } \\
\text { Divided Parts } \\
\text { of Building }\end{array}$ & Rooms & $\begin{array}{l}\text { Circulation } \\
\text { Spaces }\end{array}$ & $\begin{array}{l}\text { External } \\
\text { Spaces }\end{array}$ & \\
\hline $\begin{array}{l}\text { Wing } \\
\text { Bay } \\
\text { Core }\end{array}$ & $\begin{array}{l}\text { Residential unit } \\
\text { Bedroom } \\
\text { Bathroom } \\
\text { Living room } \\
\text { Kitchen } \\
\text { Closet }\end{array}$ & $\begin{array}{c}\text { Entrance hall } \\
\text { Lobby } \\
\text { Elevator shaft } \\
\text { Stair case } \\
\text { Corridor } \\
\text { Balcony }\end{array}$ & $\begin{array}{c}\text { External } \\
\text { parking lot } \\
\text { Tennis court } \\
\text { Courtyards }\end{array}$ & $\begin{array}{c}\text { Footing } \\
\text { Floor } \\
\text { Stair } \\
\text { Roof } \\
\text { External wall } \\
\text { Internal wall } \\
\text { Ceiling } \\
\text { Slab } \\
\end{array}$ \\
\hline
\end{tabular}

Based on the concept of the facet combination of Uniclass, the primary keys (task codes) of Tasks instances are represented with variety as shown in Table 3. Depending on the characteristics of a work type or a project, a work item is combined with all or some of the location facets, such as building, floor, space, and element. For example, the work of excavation is combined with only building information to create the task information of "Bldg101-Excavation" and the task code of "W040103:B101." In addition, to present task information more specifically, more than one item can be combined to represent one facet. The example of the finish coat work in Table 3 shows the combination of

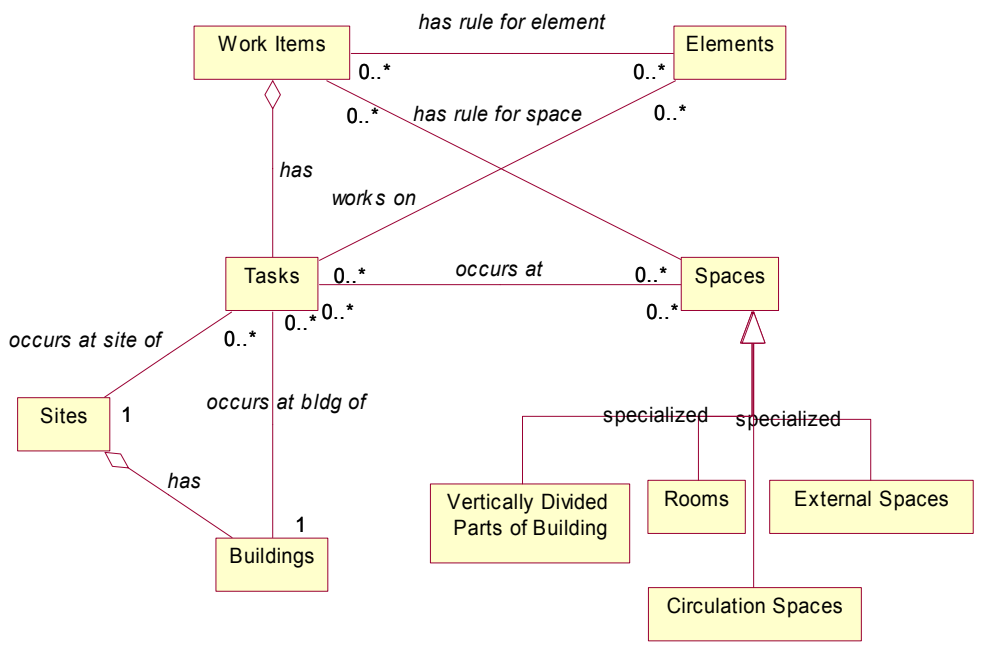

Figure 1. Task Information Model 
wall and ceiling in the element facet to create the task named "Bldg 101-Floor1-Bedroom-Wall-CeilingFinish coat."

Table 3. Examples of task information and code

\begin{tabular}{|c|c|c|c|c|c|c|c|}
\hline \multirow{3}{*}{ W } & \multicolumn{6}{|c|}{ Location facets } & \multirow{3}{*}{$\begin{array}{c}\text { Task Information } \\
\text { /Task Code }\end{array}$} \\
\hline & \multirow{2}{*}{ B } & \multicolumn{3}{|c|}{ Floor } & \multirow{2}{*}{$S$} & \multirow{2}{*}{$E$} & \\
\hline & & FB & $\mathrm{FF}$ & $\mathrm{FP}$ & & & \\
\hline $\begin{array}{l}\text { Excava- } \\
\text { tion }\end{array}$ & $\bullet$ & $x$ & $x$ & $x$ & . & . & $\begin{array}{c}\text { Bldg101-Excavation / } \\
\text { W04-01-03:B101 }\end{array}$ \\
\hline $\begin{array}{l}\text { Erect } \\
\text { rebar }\end{array}$ & $\bullet$ & $x$ & $x$ & $x$ & . & Footing & $\begin{array}{c}\text { Bldg101-Footings-Erect } \\
\text { rebar / } \\
\text { W06-01-02:B101:E15 }\end{array}$ \\
\hline $\begin{array}{l}\text { Erect } \\
\text { form }\end{array}$ & $\bullet$ & $\bullet$ & $\bullet$ & $\bullet$ & . & Slab & $\begin{array}{c}\text { Bldg 101-Floor1-Slab-Erect } \\
\text { form } \\
\text { W06-02-03:B101:FF01 }\end{array}$ \\
\hline $\begin{array}{l}\text { Finish } \\
\text { Coat }\end{array}$ & $\bullet$ & $\bullet$ & $\bullet$ & $\bullet$ & bedroom & $\begin{array}{l}\text { Wall \& } \\
\text { Ceiling }\end{array}$ & $\begin{array}{l}\text { Bldg 101-Floor1-Bedroom- } \\
\text { Wall-Ceiling-Finish coat } \\
\text { W12-01- } \\
\text { 02:B101:FF01:S511:E15:E } \\
02\end{array}$ \\
\hline $\begin{array}{l}\text { Ceramic } \\
\text { tile }\end{array}$ & $\bullet$ & $\bullet$ & $\bullet$ & $\bullet$ & $\begin{array}{l}\text { Bedroom } \\
\text { \&Kitchen }\end{array}$ & & $\begin{array}{c}\text { Bldg 101-Floor1-Bedroom- } \\
\text { Kitchen-Ceramic tile / } \\
\text { W18-03- } \\
\text { 01:B101:FF01:S505-S508 }\end{array}$ \\
\hline $\begin{array}{l}\text { W: Wo } \\
\text { B: Buil } \\
\text { FB:Bas } \\
\text { FF:1st } \\
\text { FP:Per } \\
\text { S:Spac } \\
\text { E:Elem }\end{array}$ & $\begin{array}{l}\text { k ite } \\
\text { ling } \\
\text { em } \\
\text { loo } \\
\text { tho } \\
\text { e }\end{array}$ & $\begin{array}{l}\text { nt } \\
\text { and } \\
\text { se }\end{array}$ & bove & & & & \\
\hline
\end{tabular}

\section{TASK GENERATOR}

Based on the task information model described above, an information system, called Interactive Task Generator (ITG), was developed to generate task information that can be managed in daily reporting process. The system enables a user to define rules for each work type at a standard level, and then to modify them depending on the characteristics of a project to create task information at a project level. The details on ITG are described in the followings.

\subsection{System architecture}

For the development of ITG, Microsoft SQL 2000 was used for database, and C\# of Visual Studio .Net was used for system programming. ITG has two modes: the first one is a standard mode where rules for combination of location facets, such as building, floor, space and element, are assigned and managed in each work type at a standard level; and the second one is a project mode where rules can be modified and task information is generated based on the project information, such as the number of buildings, the number of floors in each building, spaces, and elements.

\subsection{ITG system}

Figure 2 shows generating tasks for the ceramic tile work. A user selects a work item in the "Workitems" tree view, and manages rules by changing selections on "Site/Building," "Spaces," and "Elements" for the selected work item. Since rules have already been assigned at a standard mode, a user can modify the rules assigned by default, with regarding the characteristics of a project. Generated tasks are listed

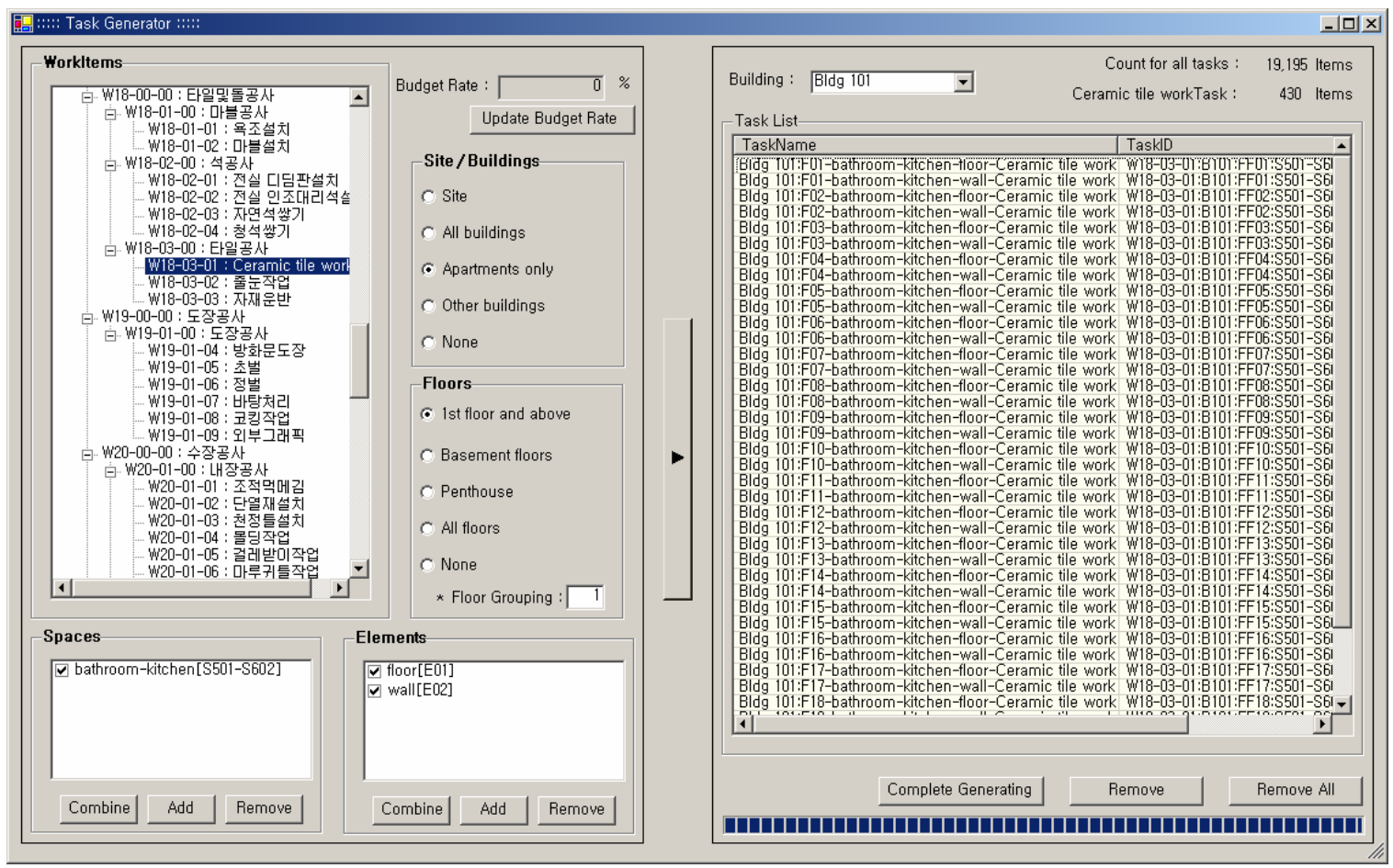

Figure 2. Task Generator 
on the right side of the window, and the number of generated tasks for the selected work item and the total number of all tasks are shown at the upper right corner.

Considering the rules, "Site/Buildings" specifies whether a work item is divided at the site or building level, while "Floors" enables to manage tasks by floors in various options: tasks for the $1^{\text {st }}$ and above floors only, for basement floors only, for penthouse only, and for all floors. In addition, "Floor Grouping" enables to create tasks by a group of more than two floors. Meanwhile, "Spaces" and "Elements" provide a way to variously combine items for each as shown in Table 3.

Furthermore, ITG allows a user to gradually create tasks for a work item by changing the rule options. For example, if a basement structure of a building is a beam and slab system while a structure at the upper ground level is a cross wall system, a user can create tasks of basement floors first, and, in turn, he/she can create tasks of 1st floor and above only as shown in Figure 3. Also, a user can delete specific tasks and generate new ones with different rule options. In this manner, ITG provides a user with an interactive way to handle tasks for each work item.

The number of generated tasks as well as the detail level of each task can be varied by the combination of location facets. If tasks are generated at more detailed level, the number of tasks will increase and become a burden to the progress management. However, in the opposite case, tasks will not be used effectively for the management. At this time, the tradeoff between the number of tasks and the detail levels of tasks are dependent on trial and error. Optimizing them through an objective evaluation method could make the progress management even more effective and efficient.

\subsection{Validation and verification}

ITG was validated through a pilot test at an apartment construction project in Osan, Korea. The construction project has seven of 20-story buildings and three of 25-story buildings with reinforced concrete structures. The test was performed with a focus on whether the rules for tasks are appropriate, and tasks can be generated with meeting the characteristics of the project. Tasks were generated for total 125 work items in the architecture discipline. The first test was performed with setting the rules as detailed as possible without any combination in each facet of space and element, and a total of 38,845 tasks were generated. In the second test, a practitioner modified the rules by combining items in each of space and element facets to make tasks more manageable and applicable at practice. As a result, total 19,195 tasks were generated. This shows that the number of tasks generated for a project can be optimized depending on how space and element items are selected and combined.

Furthermore, considering the schedule of the construction project, the maximum number of tasks for 10 days is 772 , and they occur during finish and interior works. Since most of tasks have the duration of only one or two days, about 150 tasks are to be checked by resident engineers. The total number of generated tasks in this project, which is 19,195, might seem to be huge, however, the number of tasks

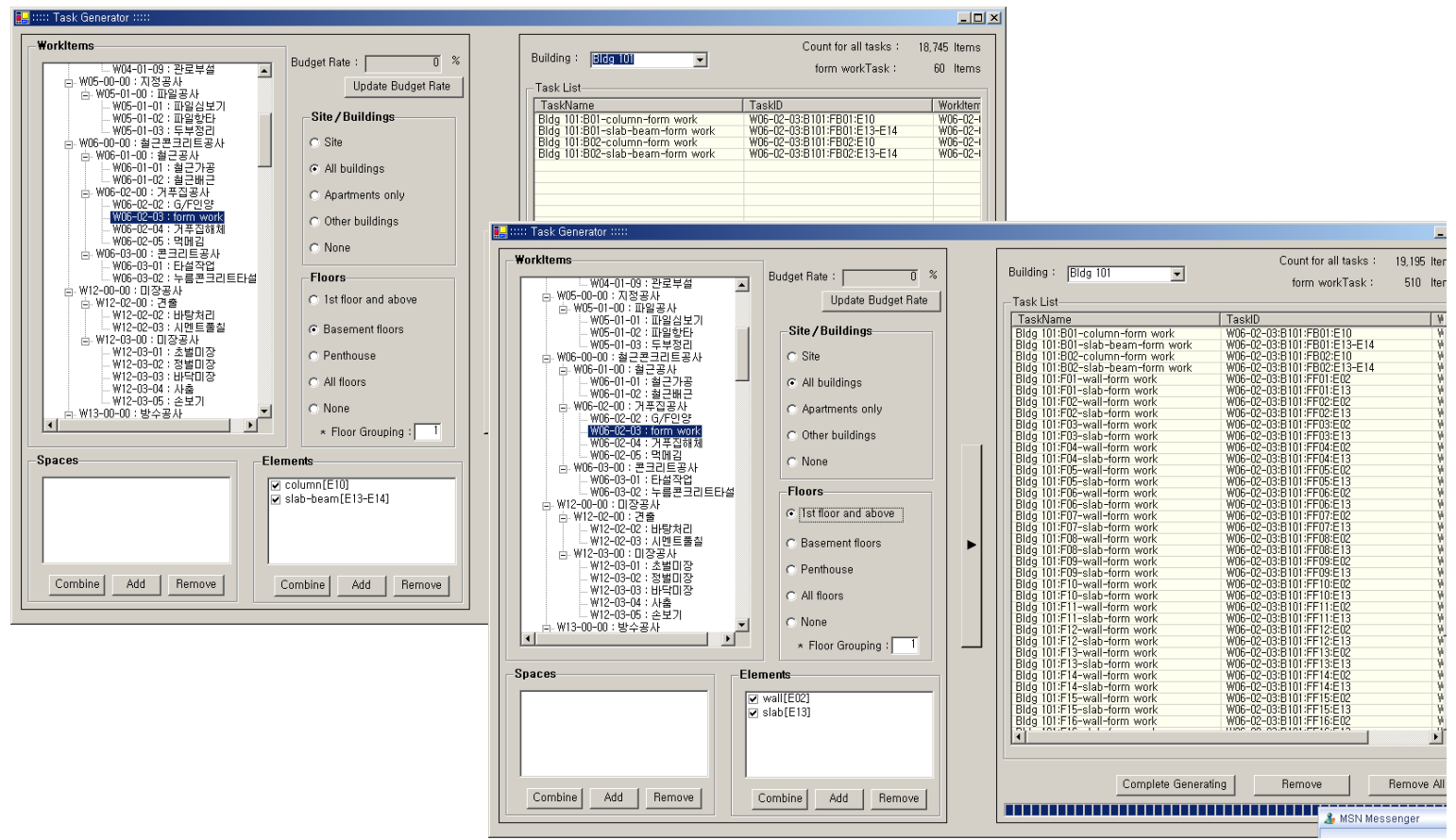

Figure 3. Task Generator 
to be checked at a peak day is about 150, and they are divided by the number of resident engineers working on daily checking. In the pilot project, since there were four engineers, they checked about 37-38 tasks per person at the peak time. In addition, tasks with more detailed information could improve the overall daily reporting process since tasks are presented in a more specific and accurate way. This would improve the communication with project participants as well, since more specific and consistent task information is shared and communicated among them.

\section{CONCLUSIONS}

This research developed an information model and a system to generate task information for more effective and efficient daily reporting. The information model was built on the basis of the combination of a work type with location facets, such as the site, building, floor, space, and element, by adopting the facet-based concept from Uniclass and the element hierarchy from IFC. A task generator called ITG was developed to manage rules for location facets of each work type as well as to generate tasks depending on the characteristics of a given project. The model and the system were successfully tested at a real construction project for validation and verification.

The task information model proposed in this research is being incorporated into a daily reporting system where all tasks are generated at the early stage of a project, and on each day tasks to be performed is selected and checked by engineers as the project goes on. The model could be further utilized for generating activities by controlling the combination of location facets or easily integrated with activities since task are sub-activities.

\section{ACKNOWLEDGEMENTS}

This work was financially supported jointly by the Ministry of Construction and Transportation of the Korean government, KICTTEP, and Woonam Construction Corporation (R\&D 2001 D-02). This is also partly supported by Brain Korea 21 (D184). The authors gratefully acknowledge the construction practitioners for their interviews and feedbacks during the research.

\section{REFERENCES}

[1] Popescu, M. C., and Charoenngam, C. Project planning, scheduling, and control: encyclopedia of terms \& applications, 1st edition, John Wiley \& Sons, Inc., 1995

[2] Russell, A, D. and Wong, W. C. M "A new generation of planning structure," Journal of
Construction Engineering and Management, ASCE, 119(2), pp. 196-214, 1993

[3] Liu, L.Y., Stumpf, A.L., Chin, S.Y., Ganeshan, R., Hicks, D. "Construction Daily Log Management System Using Multimedia," Proceedings of the Second Congress for Computing in Civil Engineering, pp. 1084-1089, Atlanta, Georgia, June 5-8, 1995

[4] Shiau, Y.C. and Wang, W.C. "Daily Report Module for Construction Management Information System," Proceedings of the $20^{\text {th }}$ International Symposium on Automation and Robotics in Construction, pp. 603-609, 2003

[5] Nader N. Chehayb and Siman M. AbouRizk "Simulation-based Scheduling with Continuos Activity Relationships" Journal of Construction Engineering and Management, ASCE, Vol. 124, No. 2, March 1998

[6] Peña-Mora, F. and Dwivedi, G. H. "Multiple Device Collaborative and Real Time Analysis System for Project Management in Civil Engineering," Journal of Computing in Civil Engineering, Vol. 16, No. 1, pp. 23-38, January 2002

[7] Crawford, M., Cann J. and O'Leary R. Uniclass: Unified Classification for the Construction Industry, First edition, RIBA Publications, 1997

[8] International Alliances for Interoperability, http://www.iai-international.org, 2004

[9] Kang, L.S. and Paulson B.C. "Adaptability of Information Classification system for Civil Works" Journal of Construction Engineering and Management, Vol. 123, No. 4, pp. 419-426, December 1997

[10] Kang, L.S. and Paulson B.C. "Information Classification For Engineering Projects By Uniclass" Journal of Construction Engineering and Management, Vol. 126, No. 2, pp. 158-167, March/April 2000

[11] Eastman, C.M Building product models: computer environments supporting design and construction, CRC Press LLC, 1999

[12] Quatrani, T. Visual modeling with Rational Rose 2000 and UML, Rose 2000 ed., AddisonWesley, 2000 